\title{
Real-Time Multiple Open-Switch Fault Diagnosis in Three-phase AC/DC PWM Converter for PMSG Based Grid-Connected Wind Power Generation System
}

\author{
Partha Sarati Das ${ }^{1}$ and Kyeong-Hwa Kim ${ }^{2}$ \\ ${ }^{1,2}$ Department of Electrical and Information Engineering \\ Seoul National University of Science and Technology \\ 232 Gongneung-ro, Nowon-gu, Seoul, 139-743, Korea \\ ${ }^{2}$ Corresponding Author \\ E-mail:k2h1@seoultech.ac.kr
}

\begin{abstract}
This paper proposes a new multiple open-switch fault diagnosis method and faulty switch localization algorithm in three-phase AC/DC PWM converter for permanent magnet synchronous generator (PMSG) based grid-connected wind power generation system. In the proposed scheme, the open-switch fault is detected by using normalized three-phase RMS currents and faulty switch location is identified by using normalized three-phase RMS currents as well as average phase currents. Various kinds of fault may occur in AC/DC PWM converter, which decreases the generator output power and degrades the stability in wind power generation system. In this paper, multiple as well as single open-switch fault conditions are investigated. The proposed fault detection and faulty switch localization algorithms do not require additional sensors or hardware since they use only the information on measured phase currents. In addition, they are quite simple, cost-effective and easy to use. To verify that the proposed methods are effective to detect faults and to identify the faulty switches position, the simulation results under twenty-one cases of open-switch faults are presented on different operating conditions.
\end{abstract}

Keywords: AC/DC PWM converter, Diagnosis, Fault detection, Open-switch fault, Wind Energy Conversion System (WECS)

\section{Introduction}

Renewable energy is receiving considerable attention throughout the world due to the exhaustion of fossil fuel and environmental issues. Fossil fuels are responsible for global warming because the majority of greenhouse gases come from burning fossil fuels to produce energy. In order to reduce the global warming, researchers are giving more attentions to develop the renewable energy sources like wind energy and solar energy. Nowadays, wind energy is the most fast growing energy source in the world to reduce the dependence on fossil fuels. Different types of generator based wind energy conversion system have been developed in recent years. Among them, permanent magnet synchronous generator (PMSG) based wind energy conversion system (WECS) has been attracting wide attentions. PMSG based directdrive WECS has achieved great development because of high efficiency, high power density, small size, and reduced weight. Maximum wind energy can be obtained by running the wind turbine in variable-speed mode. Figure 1 illustrates the structure of a PMSG based wind power generation system consisting of two power electronic converters. As can be shown in 
Figure 1, the power electronic devices in a WECS are composed of a generator-side converter and a grid-side inverter, which is generally referred as a back-to-back converter.

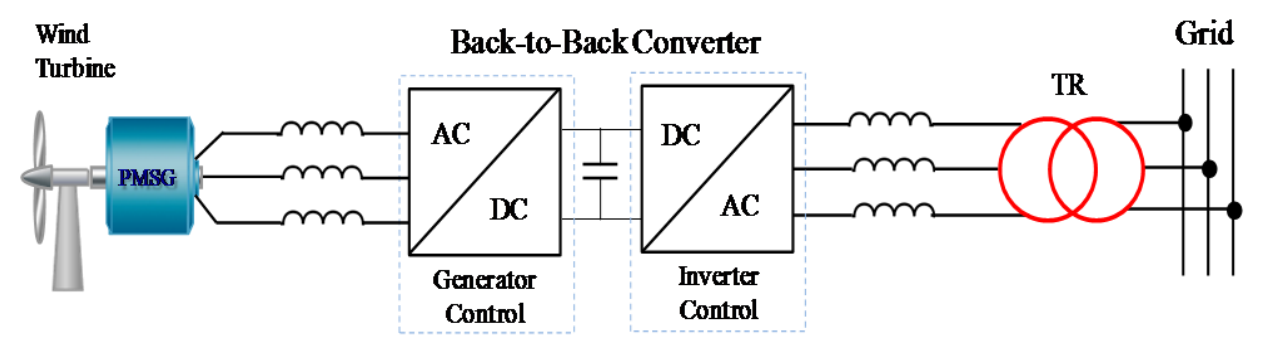

Figure 1. The Topology of PMSG based Wind Power Generation System

AC/DC PWM converter used for a generator-side converter converts the power in variable voltage and frequency into the DC voltage, which is applied to the input of the grid-side inverter. If any fault occurs in an AC/DC PWM converter without detecting it properly for a long time, it may degrade the system performance and stability. Faulty switches produce unbalanced $\mathrm{AC}$ input currents including harmonics and distortions, which may result in a severe secondary fault.

Generally, power switch failures can be classified as short-switch fault and open-switch fault. A short-switch fault generates an unbalanced over current that causes damage in other important devices of the system. Therefore, such a fault should be detected immediately to protect expensive devices. There are several reasons that cause an open-switch fault. Thermal cycling may cause lifting of bonding wires and this in turn makes an open-switch fault occur. High collector current is also another cause of an open-switch fault. Finally, the failure in gate driver circuits is one of the most common causes of open-switch fault. If any kinds of openswitch faults occur either in a generator-side converter or in a grid-side inverter, the energy supplied to the grid will be reduced continuously. There are some passive protections for the devices such as the fuses or circuit breakers. However, such a protection disconnects the power sources and the continuous operation will be stopped suddenly.

If an open-switch fault remains undetected for long period of time, it may lead to significant secondary faults in the AC/DC PWM converter or other drive components, which ends up increasing the system repairing cost. Because the energy sources with high repairing cost are not desirable, it is very essential to monitor the faults in switching device and identify the location of faulty device. An effective fault diagnosis scheme will help to reduce the repairing cost, while improving the stability and reliability of system.

Fault diagnostic methods of AC/DC PWM converter have been developed with a special focus on condition monitoring [1] and open-switch faults [2]-[3]. Also, a fault diagnostic method and fault tolerant topology have been proposed for the generator-side converter [4]. A diagnostic method for the doubly-fed wind power converter in microgrid system has been presented [5].

There has been a literature review for some IGBT fault diagnostic methods in a grid-side inverter [6]. Fault detection and isolation on a PWM inverter using the knowledge based model were investigated [7]. This scheme was based on the analysis of the current-vector trajectory and applied to a synchronous motor drive system for the fault detection and isolation. 
Several researchers investigated real-time open-circuit fault diagnosis in voltage source inverters. A new approach for real-time open-circuit fault diagnosis in voltage source inverters was proposed [8] and fault diagnosis based on the analysis of the load currents in voltage source inverters was proposed [9]. These real-time open-circuit fault diagnosis methods in voltage source inverters have been developed by using the normalized dccomponents method. Diagnostic methods for multiple open-switch faults in voltage source inverter fed motor drive system were presented in [10]-[11]. Some diagnostic methods based on the fuzzy theory and model reference adaptive system were proposed in [13]-[14]. Nowadays, multilevel AC/DC PWM converter and grid-side inverter are gaining popularity because of some advantageous features. Because it is very important to ensure the reliability and stability of system, some research works on different kinds of fault diagnosis have been done on multilevel AC/DC PWM converter and grid-side inverter. Fault detection technique in multilevel inverter was also proposed [15]. Diagnostic method for the open-switch fault in a grid-connected NPC inverter system was proposed in [16].

Generally, the fault detection for open-switch fault in single switch is much easier than the case of open-switch fault in multiple switches. There have been many researches on the open fault in single switch. On the other hand, the open fault problem in multiple switches in AC/DC PWM converter side has been studying in only a few literatures recently. Some researchers have published technical papers to address the open fault in multiple switches diagnosis problem under various fault conditions. However, little effort has been undertaken on analyzing the issues of open fault in multiple switches under various fault conditions. Although there are some studies conducted specially for various fault conditions of open fault in multiple switches, most existing detection and identification methods have problems regarding the issue of false alarms. In addition, the process for detecting fault is complex and schemes of identifying the faulty switches are insufficient. So it is necessary to design the complete algorithm with simple implementation, fast detecting time, robustness, and irrespective of operating conditions as compared with the existing methods. Considering this, this paper proposes the algorithm that can detect open fault in single as well as in multiple switches with fast detecting time without any false alarms. In order to prove the reliability and effectiveness of the proposed fault diagnostic method, twenty-one cases of open-switch faults based on different operating conditions are tested and validated.

This paper is structured as follows. In section 2, the modeling and configuration of a PMSG based wind turbine are discussed. In section 3 and section 4, the fault detection and localization algorithms of the proposed scheme are presented. To verify the effectiveness of the proposed methods, the simulation results are presented in section 5.

\section{PMSG based Variable-speed Wind Power Systems}

The output power of the wind turbine [1] is expressed as

$$
P_{\text {Tur }}=0.5 A \rho V_{\text {wind }}^{3} C_{p}(\lambda, \beta)
$$

where $A=\pi R_{b}^{2}$ is the cross sectional area of the rotor blade $\left[m^{2}\right], \rho$ is the air density $[\mathrm{kg} / \mathrm{m}], V_{\text {wind }}$ is the wind velocity $[\mathrm{m} / \mathrm{s}], C_{p}$ is the power coefficient of the turbine, $\beta$ is the pitch angle, and $\lambda$ is the tip speed ratio (TSR). The power coefficient $C_{p}$ is usually given as a function of $\lambda$ and $\beta$. The TSR $\lambda$ is given by 


$$
\lambda=\frac{\omega_{b} R_{b}}{V_{\text {wind }}}
$$

where $\omega_{b}$ is the rotational angular speed of the wind turbine.

The power captured by the wind turbine is delivered to a PMSG as a torque and the torque $T_{b}$ delivered to the PMSG can be expressed as

$$
T_{b}=P_{T u r} / \omega_{b} .
$$

In the synchronous reference frame, the stator voltage equations of the PMSG [1] are expressed as

$$
\begin{aligned}
& e_{g q}=\left(R_{g}+p L_{q}\right) i_{g q}+\omega_{r} L_{d} i_{g d}+v_{g q} \\
& e_{g d}=\left(R_{g}+p L_{d}\right) i_{g d}-\omega_{r} L_{q} i_{g q}+v_{g d}
\end{aligned}
$$

where $v_{g q}$ and $v_{g d}$ are the $q$-axis and $d$-axis stator voltages, respectively, $i_{g q}$ and $i_{g d}$ are the $q$-axis and $d$-axis stator currents, respectively, $R_{g}$ is the stator resistance, $L_{q}$ and $L_{d}$ are the $q$ axis and $d$-axis inductances, respectively, $\omega_{r}$ is the electrical angular velocity of the generator, and $p$ is a differential operator. If the generated voltage is aligned to the $q$-axis in the synchronous reference frame, $e_{g q}=\omega_{r} \lambda_{m}$ and $e_{g d}=0$ where $\lambda_{m}$ represents the flux linkage established by the permanent magnet. The electromagnetic torque of the PMSG is represented as

$$
T_{e}=1.5 n_{p}\left\{\left(L_{d}-L_{q}\right) i_{g d} i_{g q}+\lambda_{m} i_{g q}\right\}
$$

where $n_{p}$ is the number of the generator pole pairs.

For a given wind speed and pitch angle, there is an optimal TSR $\lambda_{\text {opt }}$ under which $C_{p}$ is maximum. For the maximum power extraction from the wind, the AC/DC PWM converter is controlled in order to ensure that TSR is maintained at $\lambda_{\text {opt }}$, and thus, $C_{p}$ becomes $C_{p m a x}$. Then, the maximum mechanical output power of the turbine is given as

$$
P_{b \max }=0.5 A \rho C_{p \max }\left(\frac{R_{b} \omega_{b}}{\lambda_{o p t}}\right)^{3} .
$$

From (7), the $q$-axis current reference of the PMSG can be determined as

$$
i_{g q}^{*}=\frac{T_{b \max }}{K_{t}}=\frac{P_{b \max }}{\omega_{b} K_{t}}
$$

where the symbol “*” denotes the reference quantity, $K_{b}=0.5 A \rho C_{p \max }\left(R_{b} / \lambda_{\text {opt }}\right)^{3}$, and $K_{t}=1.5 n_{p} \lambda_{m}$ is the torque constant of the PMSG.

The speed and torque controls of the PMSG are achieved through a current control of the AC/DC PWM converter. The current controller is accomplished on the synchronous reference frame using the $q$-axis current reference in (8) and the $d$-axis current reference $i_{g d}^{*}=0$ for a unit power factor. With the PI decoupling control, the voltage references are calculated as 


$$
\begin{gathered}
v_{g q}^{*}=-\left(k_{p}+\frac{k_{i}}{s}\right)\left(i_{g q}^{*}-i_{g q}\right)-\omega_{r} L_{d} i_{g d}+e_{g q} \\
v_{g d}^{*}=-\left(k_{p}+\frac{k_{i}}{s}\right)\left(i_{g d}^{*}-i_{g d}\right)-\omega_{r} L_{q} i_{g q}
\end{gathered}
$$

where $k_{p}$ and $k_{i}$ represent the proportional and integral gains, respectively, and $s$ is the Laplace operator. When (9)-(10) are applied to the voltage equations in (4)-(5), the transfer function from $i_{g q}^{*}$ to $i_{g q}$ can be obtained as

$$
T(s)=\frac{I_{g q}(s)}{I_{g q}^{*}(s)}=\frac{k_{p} s+k_{i}}{L_{q} s^{2}+\left(R_{s}+k_{p}\right) s+k_{i}} .
$$

From (11), the bandwidth of the current controller can be assigned. Also, the transfer function and bandwidth for the $d$-axis current can be determined in a similar way. In the AC/DC PWM converter, the $q$-axis and $d$-axis components of the currents control the generator torque and power factor, respectively, and the computed voltage references are applied with the space vector PWM technique.

In a variable-speed wind power generation system using the back-to-back converter, the grid-side inverter delivers the generated power to the grid with unity power factor by controlling the inverter output current in phase with the grid voltage. When the input power to the DC link becomes larger than the output power to grid, the DC link voltage is increased, and in the opposite case, the DC link voltage is decreased. By controlling the DC link voltage constantly, the grid-side inverter can deliver the power from the AC/DC PWM converter to the grid. The wind turbine and PMSG parameters are presented in Table 1.

Table 1. Wind Turbine and PMSG Parameters

\begin{tabular}{|c|c|c|}
\hline \multirow{4}{*}{ Wind turbine } & Rated power & $5 \mathrm{~kW}$ \\
\cline { 2 - 3 } & Rated wind speed & $9.5 \mathrm{~m} / \mathrm{sec}$ \\
\cline { 2 - 3 } & Rated speed & $300 \mathrm{rpm}$ \\
\cline { 2 - 3 } & Blade radius & $2.5 \mathrm{~m}$ \\
\hline \multirow{4}{*}{ PMSG } & Rated power & $5 \mathrm{~kW}$ \\
\cline { 2 - 3 } & Rated speed & $300 \mathrm{rpm}$ \\
\cline { 2 - 3 } & Number of poles & 24 \\
\cline { 2 - 3 } & Flux linkage & $0.36 \mathrm{~Wb}$ \\
\cline { 2 - 3 } & Stator resistance & $0.64 \Omega$ \\
\cline { 2 - 3 } & Stator inductance & $0.82 \mathrm{mH}$ \\
\hline
\end{tabular}

\section{Proposed Fault Detection Method}

A flow chart of the proposed fault detection algorithm is presented in Figure 2. For the open-switch fault detection, the generator three-phase currents are measured and these currents are transformed into the values on the stationary reference frame as follows:

$$
i_{d}=\frac{2}{3} i_{a m}-\frac{1}{3} i_{b m}-\frac{1}{3} i_{c m}
$$




$$
i_{q}=\frac{1}{\sqrt{3}}\left(i_{b m}-i_{c m}\right)
$$

where $i_{a m}, i_{b m}$, and $i_{c m}$ are the generator phase currents. Using these values, the Park's vector modulus $\overline{i_{s m}}$ is obtained by

$$
\overline{\left|i_{s m}\right|}=\sqrt{i_{d}^{2}+i_{q}^{2}} .
$$

To make the fault detection algorithm irrespective of operating conditions, the phase current normalization is done by dividing the generator three-phase RMS currents by the Park's vector modulus as follows:

$$
\begin{aligned}
& i_{a n}=\frac{i_{a r m s}}{\overline{\left|i_{s m}\right|}} \\
& i_{b n}=\frac{i_{b r m s}}{\overline{\left|i_{s m}\right|}} \\
& i_{c n}=\frac{i_{c r m s}}{\overline{\left|i_{s m}\right|}}
\end{aligned}
$$

where $i_{\text {arms }}, i_{b r m s}$, and $i_{c r m s}$ are three-phase RMS currents, and $i_{a n}, i_{b n}$, and $i_{c n}$ are the normalized three-phase RMS currents.

In the proposed fault detection algorithm, the three-phase currents $i_{a m}, i_{b m}$, and $i_{c m}$ are measured at first. From these values, the normalized RMS currents are calculated to be used as a fault detection variable. Under the normal operating conditions, the normalized RMS currents values become 0.7 . When an open fault is introduced in any switch, one of threephase normalized RMS currents is increased. To make sure of fault occurrence, the controller judges the fault occurrence when one of these values is larger than the threshold value $I_{t h}$ that is set as double value of normal operating conditions.

If such a condition is satisfied, the variable "fault_count" is increased. Also, to block the false alarm, the variable "fault_status" is set to one only if the variable "fault_count" is increased to more than two. This process is continuously repeated until the open-switch fault is detected. Once the fault is detected, the operating mode is changed to fault localization algorithm to investigate the fault switch.

The fault detection using this threshold value is not dependent on the operating condition because the normalized current values are employed. In addition, the choice of $I_{t h}$ as $200 \%$ of normal RMS current is very suitable in view of the practical implementation. 


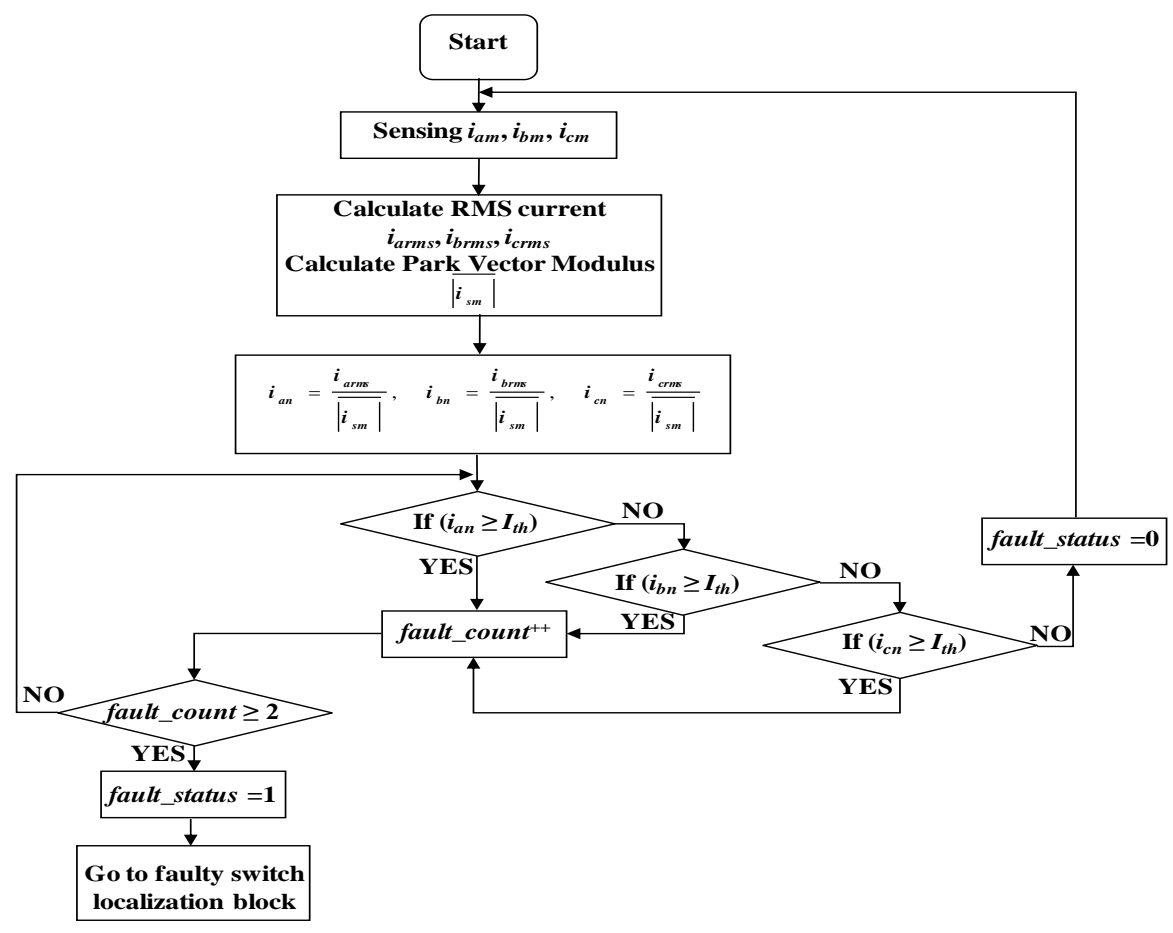

Figure 2. Flow Chart of the Proposed Open-switch Fault Detection Algorithm

\section{Proposed Fault Localization Method}

In this section, the proposed fault localization algorithm is described to identify the openswitch fault in AC/DC PWM converter. If the converter experiences an open-switch fault, it is necessary to detect the fault as soon as possible, and also, a proper action should be taken to protect the power electronics converters. Otherwise, it may produce a severe secondary fault in the entire system.

The flow charts of the proposed faulty switch localization algorithm are shown in Figure 3 and Figure 4. Figure 5 shows the configuration of three-phase AC/DC PWM converter with a proper switch symbol. Although there exist lots of situations depending on the position of faulty switches, the open-switch fault either in only one or in two switches at the same time are considered in this paper. Based on this, twenty-one cases of open-switch faults may occur. To effectively classify these cases, the open-switch fault is categorized as two groups, that is, the open fault in single switch and the open fault in multiple switches. Again, the multiple switches open fault can be subdivided by three cases. One is the case of an entire arm openswitch fault (open fault in two switches of the same converter leg). Another case is when two open-switches arise one in upper leg and the other in lower leg. The last case is when two open-switches arise either in upper leg or in lower leg. To distinguish these four faulty groups, the variable "fault_pos_mode" is defined using the switch symbol in Figure 5 as follows:

$$
\begin{aligned}
& \text { faultpos_mode }=1\left\{\left(\mathrm{~S}_{1}, \mathrm{~S}_{2}, \mathrm{~S}_{3}, \mathrm{~S}_{4}, \mathrm{~S}_{5}, \mathrm{~S}_{6}\right)\right\} \\
& \text { faultpos_mode }=2\left\{\left(\mathrm{~S}_{1}, \mathrm{~S}_{4}\right),\left(\mathrm{S}_{2}, \mathrm{~S}_{5}\right),\left(\mathrm{S}_{3}, \mathrm{~S}_{6}\right)\right\} \\
& \text { faultpos_mode }=3\left\{\left(\mathrm{~S}_{1}, \mathrm{~S}_{5}\right),\left(\mathrm{S}_{1}, \mathrm{~S}_{6}\right),\left(\mathrm{S}_{2}, \mathrm{~S}_{4}\right),\left(\mathrm{S}_{2}, \mathrm{~S}_{6}\right),\left(\mathrm{S}_{3}, \mathrm{~S}_{5}\right),\left(\mathrm{S}_{3}, \mathrm{~S}_{4}\right)\right\}
\end{aligned}
$$


fault_pos_mode $=4\left\{\left(\mathrm{~S}_{5}, \mathrm{~S}_{6}\right),\left(\mathrm{S}_{4}, \mathrm{~S}_{6}\right),\left(\mathrm{S}_{4}, \mathrm{~S}_{5}\right),\left(\mathrm{S}_{2}, \mathrm{~S}_{3}\right),\left(\mathrm{S}_{1}, \mathrm{~S}_{3}\right),\left(\mathrm{S}_{1}, \mathrm{~S}_{2}\right)\right\}$.

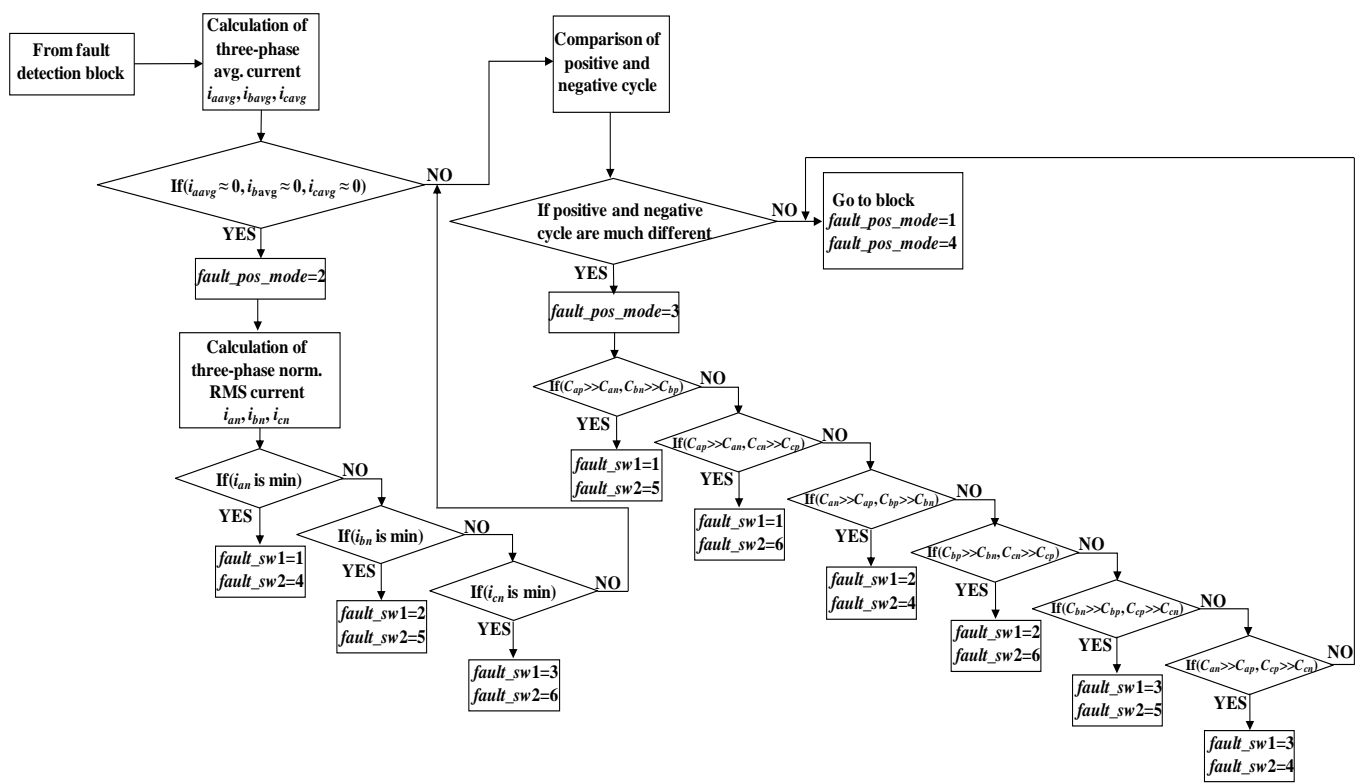

Figure 3. Flow Chart of the Proposed Faulty Switch Localization Algorithm ("fault_pos_mode"=2,3)

In above equations, the possible combinations of open-switches in each group are represented as elements. Also, typical open-switch faults for each faulty group are illustrated in Figure 5 according to the variable "fault_pos_mode".

The generator three-phase average currents and normalized RMS currents are used to identify the faulty switches. However, using these variables alone are not sufficient to perform a complete localization method to find out the faulty switches in AC/DC PWM converter since the distorted currents have various shapes according to the fault situation. For this reason, the durations of positive and negative cycles in each phase current are calculated.

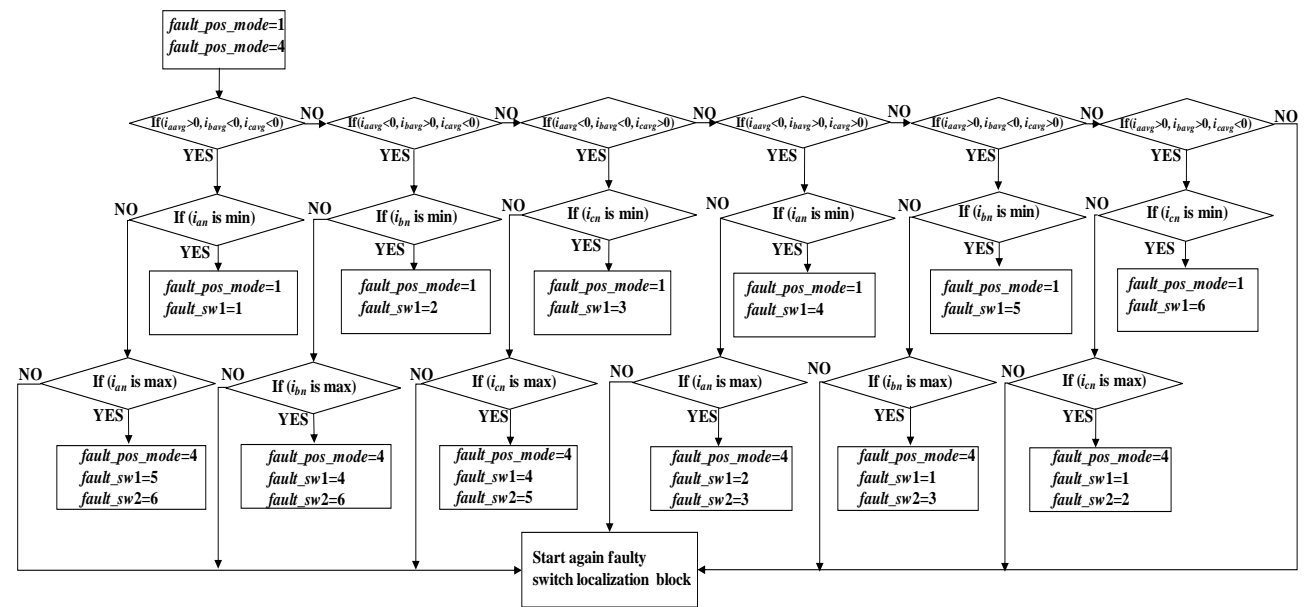

Figure 4. Flow Chart of the Proposed Faulty Switch Localization Algorithm ("fault_pos_mode"=1,4) 


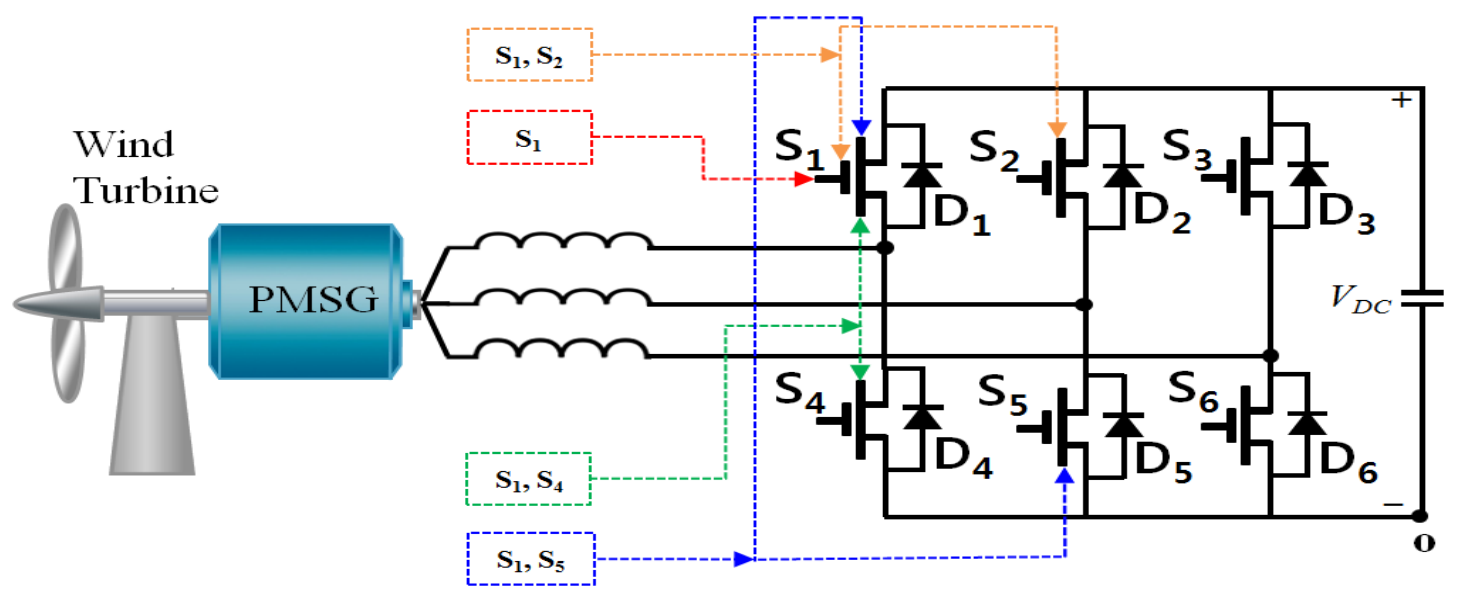

Figure 5. The Configuration of Three-phase AC/DC PWM Converter and each Faulty Group According to the Variable "fault_pos_mode"

Once the operating mode is changed to fault localization algorithm, the calculated generator three-phase average currents are used first. In the case of entire arm open-switch fault like $S_{1}$ and $S_{4}$ switches open in Figure 5, the corresponding phase current is nearly maintained to zero while the other phase currents have the same magnitude with opposite sign. Thus, by investigating whether three-phase average currents become almost zero, we can distinguish this case as "fault_pos_mode" $=2$ as shown in Figure 3. Once this fault mode is detected, the faulty switches can be easily obtained by finding the phase with the minimum RMS current. In this mode, the faulty switches will be one of three combinations $\left\{\left(S_{1}, S_{4}\right)\right.$, $\left.\left(\mathrm{S}_{2}, \mathrm{~S}_{5}\right),\left(\mathrm{S}_{3}, \mathrm{~S}_{6}\right)\right\}$.

If the condition "fault_pos_mode" $=2$ is not satisfied, the operating mode passes through another fault localization algorithm block to distinguish "fault_pos_mode" $=3$ from "fault_pos_mode" $=1$ and "fault_pos_mode" $=4$. For this purpose, the calculated durations of positive and negative cycles in each phase current are used. If these values are much different in each phase, the fault mode is confirmed as "fault_pos_mode" $=3$. By comparing these durations, the controller is able to find out the multiple faulty switches among the combination of $\left\{\left(S_{1}, S_{5}\right),\left(S_{1}, S_{6}\right),\left(S_{2}, S_{4}\right),\left(S_{2}, S_{6}\right),\left(S_{3}, S_{5}\right),\left(S_{3}, S_{4}\right)\right\}$.

If the conditions of "fault_pos_mode" $=2$ and "fault_pos_mode" $=3$ are not satisfied, another fault localization algorithm block is examined as shown in Figure 4. In Figure 4, the faulty switch localization algorithm consists of two fault modes as "fault_pos_mode" $=1$ and "fault_pos_mode" $=4$. In this flow chart, the information on the three-phase average currents and three-phase normalized RMS currents are employed to classify these two fault modes. Once the fault mode is determined, the minimum and maximum RMS currents are used to find out the faulty switches. The possible faulty switches are one among the combinations of $\left\{\left(\mathrm{S}_{1}, \mathrm{~S}_{2}, \mathrm{~S}_{3}, \mathrm{~S}_{4}, \mathrm{~S}_{5}, \mathrm{~S}_{6}\right)\right\}$ under "fault_pos_mode" $=1$, and one among the combinations of $\left\{\left(\mathrm{S}_{5}\right.\right.$, $\left.\left.\mathrm{S}_{6}\right),\left(\mathrm{S}_{4}, \mathrm{~S}_{6}\right),\left(\mathrm{S}_{4}, \mathrm{~S}_{5}\right),\left(\mathrm{S}_{2}, \mathrm{~S}_{3}\right),\left(\mathrm{S}_{1}, \mathrm{~S}_{3}\right),\left(\mathrm{S}_{1}, \mathrm{~S}_{2}\right)\right\}$ under "fault_pos_mode"=4.

\section{Fault Analysis with Simulation Results}

To verify the performance and reliability of the proposed fault detection and localization algorithms, the simulation of the PMSG based grid-connected wind power generation system was carried out using the PSIM environment. The overall system configuration is shown in Figure 1. In this paper, special attentions are given to the open-switch fault problems in 
multiple switches and detection of them. Also, to consider some features such as the robustness of the proposed diagnostic method, the effectiveness against the issue of false alarms, and its independency of the operating conditions, the operating speed are chosen at $300 \mathrm{rpm}, 200 \mathrm{rpm}$, and $150 \mathrm{rpm}$ as the generator operating conditions. For various combinations of open-switch faults, twenty-one cases of open-switch faults are considered at each different conditions.

\section{A. Open Fault in Single Switch}

The first case considered in the simulation is the open fault in single switch. This corresponds to the mode of "fault_pos_mode" $=1$ and there are six possible faulty switches for this case. The desired objective is that the controller should detect a fault as soon as possible and find faulty switches through a proper mode analysis. Figure 6 shows the simulation results when the switch $S_{1}$ in the three-phase AC/DC PWM converter has open-switch fault. The operating PMSG speed is $300 \mathrm{rpm}$ and the open-switch fault occurs at $0.2 \mathrm{sec}$. In Figure 6 , while the left figures represent some current waveforms such as three-phase currents, normalized RMS currents, and average phase currents, the right figures show flag variables developed by the proposed fault detection and localization algorithms. The flag variables consist of "fault_status" to denote whether the fault has been detected, "fault_pos_mode" to denote which type of fault has occurred among four faulty groups, and "faulty_sw" to denote the faulty switch. In the normal operation before $0.2 \mathrm{sec}$, three-phase currents are sinusoidally balanced with zero average current. However, as soon as $S_{1}$ has an open-switch fault, the negative current cycle in $a$-phase becomes distorted, resulting in the positive average current. In the AC/DC PWM converter, the positive current in $a$-phase conducts through $\mathrm{S}_{4}$ or $\mathrm{D}_{1}$, on the other hand, the negative current through $S_{1}$ and $D_{4}$. The open fault in $S_{1}$ definitely disturbs to build up sinusoidal negative current in $a$-phase as shown in Figure 6.

After $\mathrm{t}=0.2 \mathrm{sec}$, one of the normalized RMS currents reaches defined threshold value $I_{t h}$, the flag "fault_status" is readily set to one. Since the open-switch fault has been detected, the faulty switch needs to be identified through the fault localization algorithm. In this stage, the controller determines the flag "fault_pos_mode" by analyzing various information on current waveform based on the flow chart in Figure 3 and Figure 4.
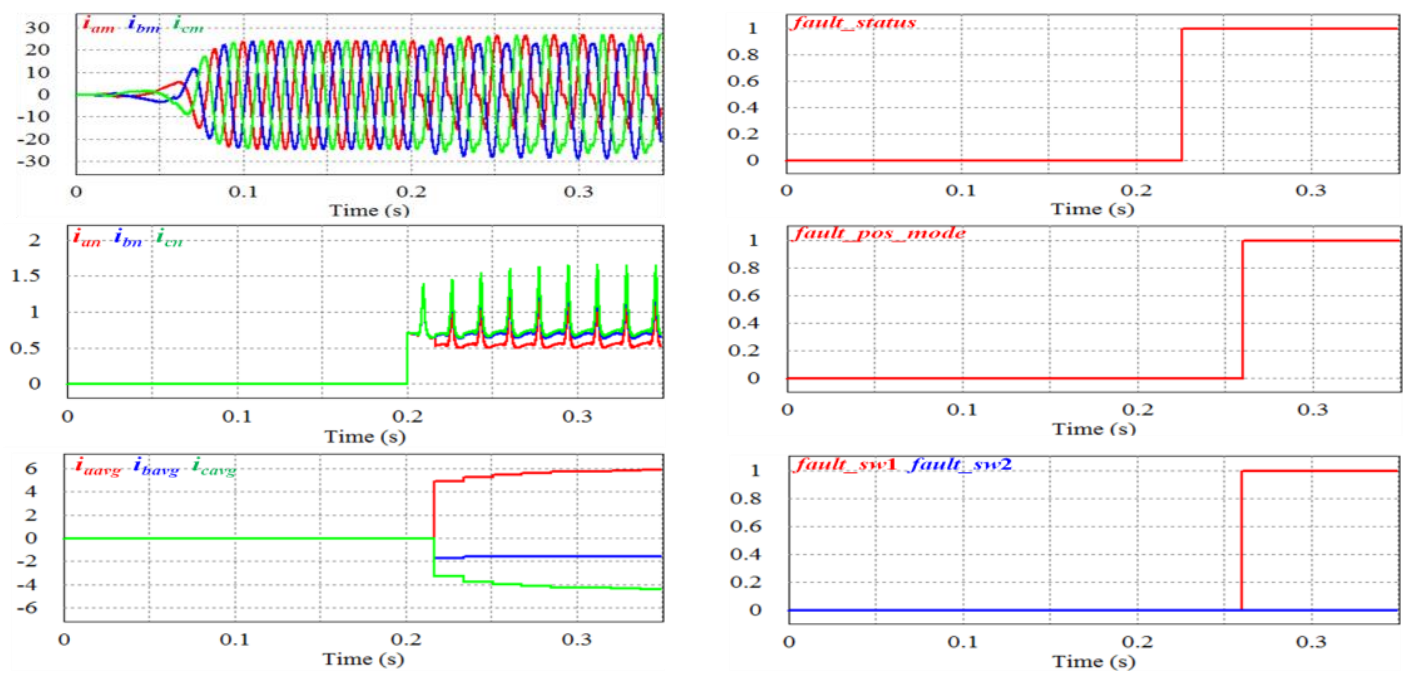

Figure 6. Simulation Results Under $S_{1}$ Open-switch Fault in the Three-phase AC/DC PWM Converter at PMSG Speed of 300 rpm 
Using the calculated three-phase average currents, the localization algorithm investigates whether three-phase average currents are close to zero. Because this is not true as shown in Figure 6, the condition of "fault_pos_mode" $=2$ is not satisfied. Again, by inspecting the durations of positive and negative cycles in each phase current, it is confirmed that the condition of "fault_pos_mode" $=3$ is not satisfied either. Finally, by analyzing the information on the average phase currents and normalized RMS current, the controller determines the "fault_pos_mode" as one and the faulty switch as $\mathrm{S}_{1}$.

\section{B. Open-switch Fault in Entire Arm}

The next case is the open-switch fault in entire arm of one phase as the faults in switches $S_{1}$ and $S_{4}$ at the same time. This corresponds to the faulty group of "fault_pos_mode" $=2$ and there are three possible faulty switches for this case as described in Figure 3. Figure 7 shows the simulation results when $S_{1}$ and $S_{4}$ have the open-switches faults at the same time. Similarly, the PMSG speed is $300 \mathrm{rpm}$ and the faults are introduced at $0.2 \mathrm{sec}$. In the normal operation before $0.2 \mathrm{sec}$, three-phase currents are sinusoidally balanced with zero average current. However, as soon as $S_{1}$ and $S_{4}$ have the open fault, distorted positive and negative current cycles in $a$-phase appear due to the inability of applying switching signals to the AC/DC PWM converter. In this case, the flag "fault_status" is easily set to one because one of the normalized RMS currents is beyond the threshold value $I_{t h}$ in very short time.
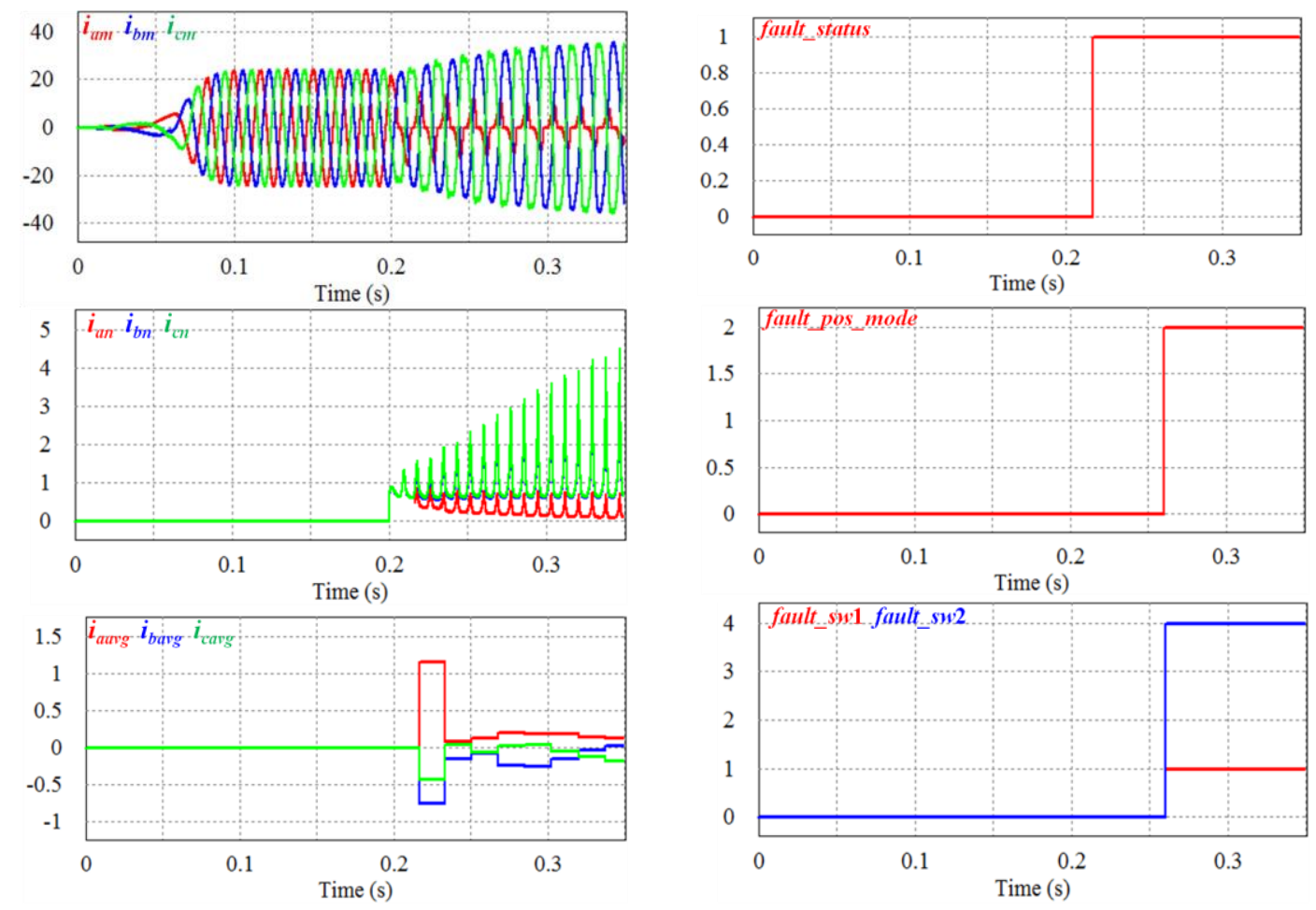

Figure 7. Simulation Results Under $S_{1}$ and $S_{4}$ Open-switches Fault in the Threephase AC/DC PWM Converter at PMSG Speed of $300 \mathrm{rpm}$ 
Once the open-switch fault is detected, the operating mode is changed to the fault localization algorithm. As is shown in Figure 7, since three-phase average currents are very close to zero, the condition of flag "fault_pos_mode" $=2$ is satisfied. Also, by finding the phase with the minimum RMS current, "fault_sw1" and "fault_sw2" can be detected as one and four as shown in the last waveform of Figure 7.

\section{Open Fault in Multiple Switches}

The last two cases are the open-switch fault in multiple switches. According to the position of faulty switch, the open fault case in multiple switches are divided by two faulty groups, which corresponds to the mode of "fault_pos_mode" $=3$ and that of "fault_pos_mode" $=4$. In each faulty group, six combinations of multiple faulty switches are possible. Figure 8 and Figure 9 show the simulation results for the fault detection under $S_{1}$ and $S_{2}$ open-switches fault at $200 \mathrm{rpm}$ and $S_{1}$ and $S_{5}$ open-switches fault at $150 \mathrm{rpm}$, respectively.
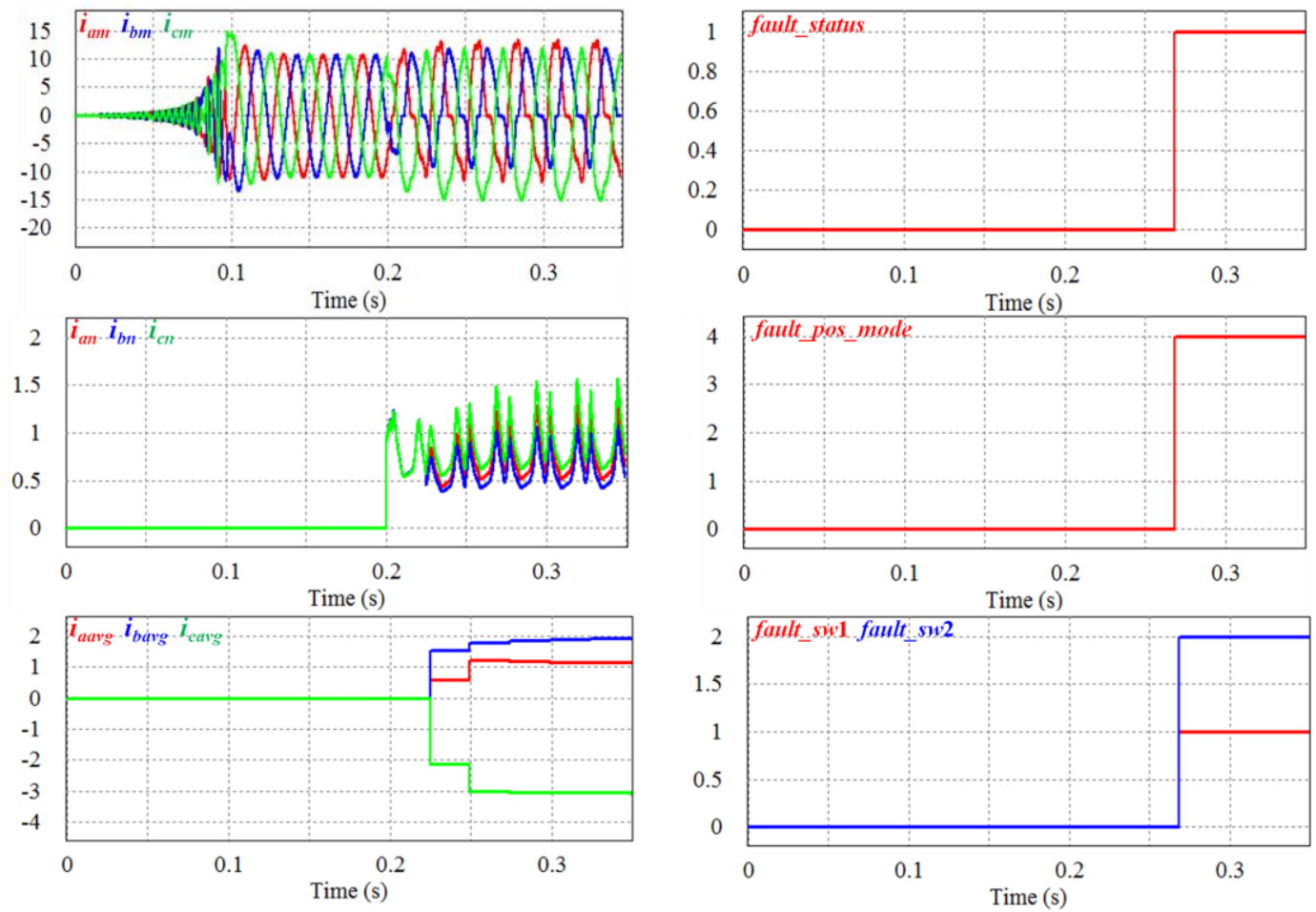

Figure 8. Simulation Results under $S_{1}$ and $S_{2}$ Open-switches Fault in the ThreePhase AC/DC PWM converter at PMSG speed of $200 \mathrm{rpm}$

It is shown in Figure 8 that the negative current periods in $a$-phase and $b$-phase are much distorted due to the open faults in $S_{1}$ and $S_{2}$. Also, as soon as the open-switch fault occurs at $0.2 \mathrm{sec}$, the normalized RMS currents are instantly increased, permitting the detection of open-switch fault. After the fault detection, the fault localization algorithm is examined to find out the faulty switches. By analyzing with three-phase average currents, the normalized RMS currents, and the durations of positive and negative cycles in each phase, the fault localization algorithm determines the flag "fault_pos_mode" as four and the faulty switch variables "fault_sw1" and "fault_sw2" as one and two as the last waveform of Figure 8. 
The results for another case of the open fault in multiple switches are shown in Figure 9. This case has two open-switches, one in upper leg and the other in lower leg. Whereas the phase with faulty switch in upper leg has positive average current, the phase with faulty switch in lower leg has negative average current. On the other hand, the average phase current without faulty switch is close to zero. By using the similar process as presented in previous fault case, the open fault can be detected successfully. Similarly, by analyzing with various information on current, the proposed algorithm concludes that the flag "fault_pos_mode" is three and the faulty switch variables "fault_sw1" and "fault_sw2" are one and five, respectively as shown in Figure 9.
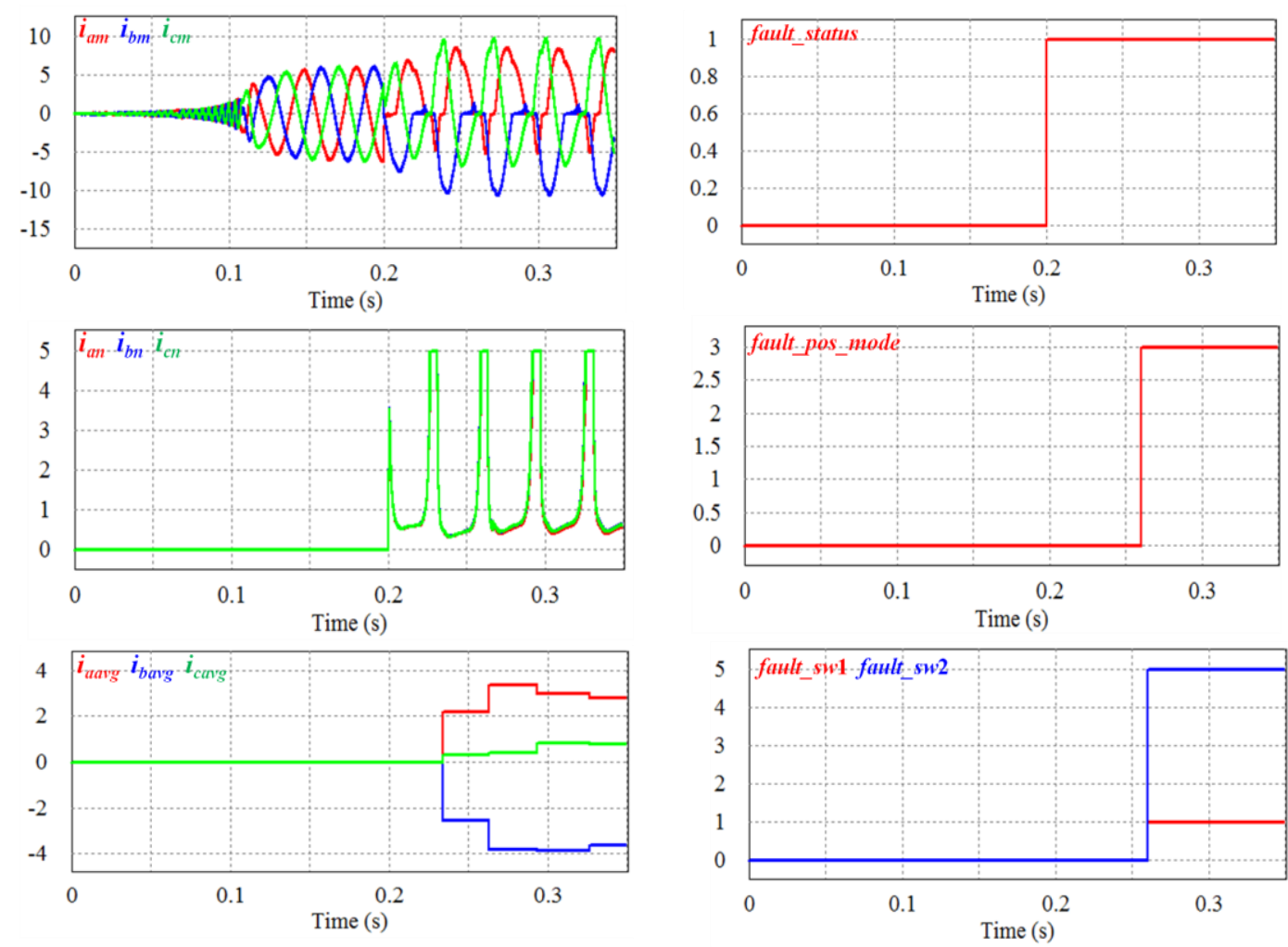

\section{Figure 9. Simulation Results under $S_{1}$ and $S_{5}$ Open-switches Fault in the Three- phase AC/DC PWM Converter at PMSG Speed of 150 rpm}

When we consider the open-switch fault either in only one or in two switches at the same time, there exist twenty-one cases of open-switch faults in AC/DC PWM converter. Even though the detection results have been presented in Figure 6 through Figure 9 under only four fault conditions among them, the proposed algorithm still works well under the other openswitch fault conditions. Table 2 summarizes the test results under twenty-one cases of openswitch faults at operating speed of $200 \mathrm{rpm}$. Through these test results, it is proved that the proposed scheme can effectively detect the open-switch faults and find the faulty switch within short time. Table 2 also presents the total time including the fault detection and fault localization as well as the detection parameters used for the localization algorithm. 
Table 2. Test Results Under 21 Cases of Open-switch Faults

\begin{tabular}{|c|c|c|c|c|}
\hline Faulty switches & Total time [ms] & fault_pos_mode & fault_sw1 & fault_sw2 \\
\hline $\mathrm{S}_{1}$ & 69.97 & 1 & 1 & None \\
\hline $\mathrm{S}_{2}$ & 59.96 & 1 & 2 & None \\
\hline $\mathrm{S}_{3}$ & 61.57 & 1 & 3 & None \\
\hline $\mathrm{S}_{4}$ & 60.00 & 1 & 4 & None \\
\hline $\mathrm{S}_{5}$ & 59.96 & 1 & 5 & None \\
\hline $\mathrm{S}_{6}$ & 60.00 & 1 & 6 & None \\
\hline $\mathrm{S}_{1}, \mathrm{~S}_{4}$ & 59.66 & 2 & 1 & 4 \\
\hline $\mathrm{S}_{2}, \mathrm{~S}_{5}$ & 64.12 & 2 & 2 & 5 \\
\hline $\mathrm{S}_{3}, \mathrm{~S}_{6}$ & 60.00 & 2 & 3 & 6 \\
\hline $\mathrm{S}_{1}, \mathrm{~S}_{5}$ & 59.96 & 3 & 1 & 5 \\
\hline $\mathrm{S}_{1}, \mathrm{~S}_{6}$ & 59.96 & 3 & 1 & 6 \\
\hline $\mathrm{S}_{2}, \mathrm{~S}_{4}$ & 60.00 & 3 & 2 & 4 \\
\hline $\mathrm{S}_{2}, \mathrm{~S}_{6}$ & 59.96 & 3 & 2 & 6 \\
\hline $\mathrm{S}_{3}, \mathrm{~S}_{5}$ & 60.00 & 3 & 3 & 5 \\
\hline $\mathrm{S}_{3}, \mathrm{~S}_{4}$ & 59.66 & 3 & 3 & 4 \\
\hline $\mathrm{S}_{1}, \mathrm{~S}_{2}$ & 68.27 & 4 & 1 & 2 \\
\hline $\mathrm{S}_{1}, \mathrm{~S}_{3}$ & 60.07 & 4 & 1 & 3 \\
\hline $\mathrm{S}_{2}, \mathrm{~S}_{3}$ & 59.96 & 4 & 2 & 3 \\
\hline $\mathrm{S}_{4}, \mathrm{~S}_{5}$ & 60.00 & 4 & 4 & 5 \\
\hline $\mathrm{S}_{4}, \mathrm{~S}_{6}$ & 59.66 & 4 & 4 & 6 \\
\hline $\mathrm{S}_{5}, \mathrm{~S}_{6}$ & 60.00 & 4 & 5 & 6 \\
\hline & & & & \\
\hline
\end{tabular}

\section{Conclusions}

This paper proposes a new fault detection and localization method under the open fault in multiple switches in three-phase AC/DC PWM converter for wind power generation system. Various kinds of fault may occur in AC/DC PWM converter, which decreases the generator output power and degrades the stability in wind power generation system. In this paper, multiple as well as single open-switch fault conditions are investigated. By analyzing various informations on current waveforms, the proposed scheme is able to detect the open-switch fault and find the faulty switch in multiple switches as well as in single switch irrespective of operating conditions. The proposed fault detection and localization algorithms do not require any additional sensors or hardware since they use only the information on measured phase currents. The proposed algorithms require only simple mathematical operations with the reduced computational efforts, which makes the proposed diagnosis quite simple and costeffective. It can be easily implemented into the main controller without any complexity to improve the reliability of the practical three-phase AC/DC PWM converter. Twenty-one cases of open faults in multiple switches as well as in single switch are used for test conditions. The simulation results under different operating conditions have been presented to prove the effectiveness of the proposed scheme and its independence on operating conditions.

\section{Acknowledgements}

This study was supported by the Research Program funded by the Seoul National University of Science and Technology. 


\section{References}

[1] K. H. Kim, "Int. J. of Control and Automation", Performance Investigation and Observer-based Condition Monitoring Scheme for a PMSG-based Grid-connected Wind Power System under Switch Open Fault, vol. 6, no. 4, (2013).

[2] W. S. Im, J. S. Kim, J. M. Kim, D. C. Lee and K. B. Lee, “Journal of Power Electronics”, Diagnosis Methods for IGBT Open Switch Fault Applied to Three-phase AC/DC PWM Converter, vol. 12, no. 1, (2012).

[3] N. M. A. Freire, J. O. Estima and A. J. M. Cardoso, "IEEE Trans. on Industry Electronics", Open-Circuit Fault Diagnosis in PMSG Drives for Wind Turbine Applications, vol. 60, no. 9, (2013).

[4] W. S. Im, J. M. Kim, D. C. Lee and K. B. Lee, "IEEE Trans. on Industry Applications", Diagnosis and Faulttolerant Control of Three-phase AC-DC PWM Converter Systems, vol. 49, no. 4, (2013).

[5] P. Duan, K. Xie, L. Zhang and X. Rong, "IEEE Trans. on Power Electronics", Open-switch Fault Diagnosis and System Reconfiguration of Doubly fed Wind Power Converter Used in a Microgrid, vol. 26, no. 3, (2011).

[6] B. Lu and S. K. Sharma, "IEEE Trans. on Industry Electronics" A Literature Review of IGBT Fault Diagnostic and Protection Methods for Power Inverters, vol. 45, no.5, (2009).

[7] R. Peuget, S. Courtine and J. P. Rognon, "IEEE Trans. on Industry Applications", Fault Detection and Isolation on a PWM Inverter by Knowledge-based Model, vol. 34, no. 6, (1998).

[8] J. O. Estima and A. J. M. Cardoso, "IEEE Trans. on Industry Applications", A New Approach for Real-time Multiple Open-circuit Fault Diagnosis in Voltage-source Inverters, vol. 47, no. 6, (2011).

[9] W. Sleszynski, J. Nieznanski and A. Cichowski, "IEEE Trans. on Industrial Electronics", Open-Transistor Fault Diagnostics in Voltage-source Inverters by Analyzing the Load Currents, vol. 56, no. 11, (2009).

[10] R. L. A. Ribeiro, C. B. Jacobina, E. R. C. Silva and A. M. N. Lima, "IEEE Trans. on Power Elecronics", Fault Detection of Open-switch Damage in Voltage-fed PWM Motor Drive Systems, vol. 18, no. 2, (2003).

[11] J. O. Estima and A. J. M. Cardoso, "IEEE Trans. on Industrial Electronics", A New Algorithm for Real-time Multiple Open-circuit Fault Diagnosis in Voltage-fed PWM Motor Drives by the Reference Current Errors, vol. 60 , no. $8,(\mathbf{2 0 1 3})$.

[12] F. Zidani, D. Diallo, M. E. H. Benbouzid and R. Naït-Saïd, "IEEE Trans. on Industrial Electronics", A Fuzzybased Approach for the Diagnosis of Fault Modes in a Voltage-fed PWM Inverter Induction Motor Drive, vol. 55 , no. 2, (2008).

[13] S. M. Jung, J. S. Park, H. W. Kim, K. Y. Cho and M. J. Youn, "IEEE Trans. on Power Electronics", An MRAS-based Diagnosis of Open-circuit Fault in PWM Voltage-source Inverters for pm Synchronous Motor Drive Systems, vol. 28, no. 5, (2013).

[14] S. Khomfoi and L. M. Tolbert, "IEEE Trans. on Industrial Electronics", Fault Diagnosis and Reconfiguration for Multilevel Inverter Drive using AI-based Techniques, vol. 54, no. 6, (2007).

[15] Q. T. An, L. Z. Sun, K. Zhao and L. Sun, "IEEE Trans. on Power Electronics”, Switching Function Modelbased Fast-diagnostic Method of Open-switch Faults in Inverters without Sensors, vol. 26, no. 1, (2011).

[16] U. M. Choi, H. G. Jeong, K. B. Lee and F. Blaabjerg, "IEEE Trans. on Power Electronics", Method for Detecting an Open-switch fault in a Grid-connected NPC Inverter System, vol. 27, no. 6, (2012).

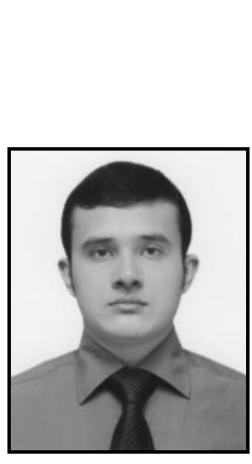

\section{Authors}

Partha Sarati Das was born in Chandpur, Bangladesh, in 1986. He received the M.Eng. degree in electrical and electronic engineering from Dhaka University of Engineering and Technology, Gazipur, Bangladesh, in 2012. currently he is working toward the M.S. degree in the Department of Electrical and Information Engineering at Seoul National University of Science and Technology. His research interests include renewable energy, power electronics, wireless power transmission, VLSI circuits (analog \& digital). 


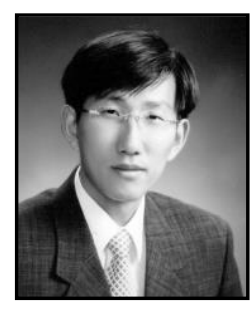

Kyeong-Hwa Kim was born in Seoul, Korea, in 1969. He received the B.S. degree from Hanyang University, Seoul, Korea, and the M.S. and Ph.D. degrees from KAIST, Taejon, Korea, in 1991, 1993, and 1998, respectively, all in electrical engineering. From 1998 to 2000, he was a Research Engineer with Samsung Electronics Company, where he was engaged in research and development of AC machine drive systems. From 2000 to 2002, he was a Research Professor with KAIST. Since August 2002, he has been with Seoul National University of Science and Technology, where he is currently a Professor. His current research interests are in the areas of $\mathrm{AC}$ machine drive, control, diagnosis, power electronics, renewable energy, and DSP-based control applications. Prof. Kim is a member of the Korean Institute of Power Electronics (KIPE). 